\title{
Efficacy of Periconceptional High-Dose Folic Acid in Isolated Orofacial Cleft Prevention: A Systematic Review
}

\author{
Rajshree Jayarajan ${ }^{1}$ Anantharajan Natarajan² Ravindranathan Nagamuttu² \\ ${ }^{1}$ Department of Plastic Surgery, University Hospitals of Leicester, \\ Address for correspondence Rajshree Jayarajan, MCh, FEBOPRAS, \\ Leicester, United Kingdom \\ 2Maxillofacial, Facial Plastic and Reconstructive Surgery Centre, \\ Pantai Jerudong Medical Centre, Brunei Darussalam \\ Department of Plastic Surgery, University Hospitals of Leicester, \\ Leicester LE1 5WW, United Kingdom (e-mail: rajshreecj@gmail.com).
}

Indian J Plast Surg 2019;52:153-159

\begin{abstract}
Background The effectiveness of folic acid in prevention of neural tube defects has been well established. Periconceptional supplementation of folic acid in low doses has been shown to be effective in some studies on its efficacy in prevention of occurrence of clefts. There are few studies on high-dose folic acid for prevention of occurrence and recurrence of clefts in high risk cases and the overall consensus based on these is not available.

Objectives The aim of this review is to assess whether high-dose folic acid supplementation during the periconceptional period reduces the risk of occurrence of nonsyndromic clefts and recurrence in high-risk cases.

Search Methods Search was conducted in the various databases and trial registers. There were no restrictions in the search with regards to language, study setting, or date of publication.

Results The search yielded four studies-one randomized control trial, two prospective control trials, and a case-control surveillance on screening 401 articles. The three case-control studies were specifically on recurrence of clefts in high risk cases. The heterogeneity of the studies prevented conduction of a meta-analysis. But results of the studies demonstrate a strong association between high-dose folic acid and isolat-

Keywords

- periconception

- high-dose folic acid

- cleft lip

- cleft palate ed nonsyndromic cleft lip with or without cleft palate $(C L \pm C P)$. But such an effect is weak with regards to isolated cleft palate (CP).

Conclusions With the limited evidence available, our conclusion is that high-dose folic acid probably has a role in prevention of recurrence of isolated $C L \pm C P$ in high-risk individuals, but not CP.
\end{abstract}

\section{Introduction}

Orofacial cleft is a common congenital anomaly of the craniofacial region-the incidence being between 1 in 300 live births to 1 in 1,000 . A child born with a cleft has to undergo several surgical procedures over a period of time for correction of the deformities and in addition to this, there are other hospital visits required for associated issues. This situation is financially and emotionally draining resulting in
DOI https://doi.org/

$10.1055 / \mathrm{s}-0039-1696864$

ISSN 0970-0358. significant reduction in the quality of life of the patients and their family members. ${ }^{1,2}$ Therefore, prevention of clefts is of utmost importance as a public health issue.

The cascade of processes leading to development of normal lip and palate are intricate, and prone to disruption at various stages resulting in specific deformities. Orofacial cleft includes cleft of the lip with or without palate and cleft palate alone. These two entities have differences in embryonic origin and differences in the recurrence rates.
(C)2019 Association of Plastic Surgeons of India
License terms

()(1) $\ominus \circledast$ 
The etiology of clefts is linked to genetic and environmental factors. Of the environmental factors, one which can be easily manipulated is the folic acid link.

A study of susceptibility genes for cleft lip and palate has attempted to correlate specific gene variants with specific environmental risk factors. ${ }^{3}$ Thus, some genetic variants are associated with a background risk which is manifested when exposed to a particular environmental factor. The genes found to be associated with folic acid in this way are MTHFR and $R F C 1$. $^{4-7}$

The recommended dose of folic acid in females of childbearing age for prevention of neural tube defects is 400 micrograms daily before conception to week 12 of pregnancy. In those with high risk of neural tube defects, the dose is $5 \mathrm{mg}$ (British National Formulary). Low doses of folic acid have been shown to prevent neural tube defects (NTD) and high doses the recurrence of NTD. ${ }^{8}$ There is no such evidence based folic acid dose prescribed for oral cleft occurrence or recurrence. Recurrence which is the occurrence of clefts in members of affected families is higher by 40 times that of the general population.

There have been several studies reporting the effects of multivitamins containing folic acid on clefts. Wilcox et a ${ }^{9}$ reported reduced risk of isolated cleft lip with or without cleft palate by a third with folic acid ( 400 micrograms) supplementation during early pregnancy, but no protection against cleft palate alone. In a case-control study to determine the association between nonsyndromic clefts and folic acid, Little et al have concluded that higher intake of folate does not appear to prevent clefts ${ }^{10}$ while a study in Netherlands demonstrated that periconceptional maternal folic acid supplement was beneficial to reduce the risk for CLP. ${ }^{11} \mathrm{~A}$ Cochrane's review on periconceptional folic acid on a regular dosage ${ }^{12}$ showed no evidence of any preventive effects on cleft palate. A recent meta-analysis by Jahanbin et al ${ }^{13}$ have shown that periconceptional multivitamin containing folic acid has a protective effect on oral clefts.

A cohort-controlled study by Czeizel et $\mathrm{a}^{14}$ of multivitamin intervention, no significant effect was found for low dose of folic acid on prevention of oral clefts. But high dose of folic acid ( $6 \mathrm{mg}$ ) was found to prevent some orofacial clefts. ${ }^{15}$ Most studies-case-control and observational-have reported on doses of folic acid less than $1 \mathrm{mg}$ and many have not reported the dose of folic acid used in their studies. There is a dilemma regarding whether low dose or high dose of folic acid is required in prevention of orofacial clefts.

A systematic review and meta-analysis by Johnson and Little ${ }^{16}$ has shown no strong evidence regarding association between folic acid and oral clefts. The dosage of folic acid in the various studies ranged from 0.5 to $10 \mathrm{mg}$ and no dose dependent difference was found in their analysis. But they have concluded that multivitamins in early pregnancy may have a protective effect on clefts, especially $\mathrm{CL} \pm \mathrm{CP}$.

We postulate that a high dose of folic acid in the periconceptional period is required to reduce the occurrence and recurrence of isolated nonsyndromic cleft.

\section{Methods}

Protocol was registered on the PROSPERO register of systematic reviews (CRD 42018090927).

PRISMA-P guidelines for the conduct of systematic review and meta-analysis protocol were followed.

\section{Search Strategy}

The following electronic databases were searched:

- Cochrane, Medline, EMBASE, LILACS BIREME (Latin American and Caribbean Health Science Information database).

- Ongoing trials: World Health Organization International Clinical Trials Registry Platform, U.S. National Institutes of Health Ongoing Trials Register.

- The metaRegister of Controlled Trials.

- The US National Institutes of Health Ongoing Trials Register ClinicalTrials.gov.

- The Australian New Zealand Clinical Trials Registry.

- The World Health Organization International Clinical Trials Registry Platform.

- The EU Clinical Trials Register.

There were no restrictions in the search with regards to language, study setting, or date of publication.

\section{Study Selection}

Studies were selected based on the following criteria: human studies assessing the effectiveness of administration of highdose folic acid in prevention of nonsyndromic cleft lip with or without cleft palate $(\mathrm{CL} \pm \mathrm{CP})$ and cleft palate $(\mathrm{CP})$ were included. Studies that did not meet the inclusion criteria, review articles, case reports, editorials, and letters were excluded.

The population of interest was females of reproductive age group who were at high-risk of having a child with nonsyndromic $\mathrm{CL} \pm \mathrm{CP}$ or isolated $\mathrm{CP}$.

A three stage review process was followed. During the initial stage the titles were reviewed by two reviewers and the articles not relevant to the review were excluded. In the second stage, the abstracts of the selected articles were reviewed against the inclusion criteria ( - Fig. 1: PRISMA-P flow diagram). The final stage consisted of detailed review of the full texts selected by both reviewers. Discrepancies that arose were dealt with by discussion.

\section{Data Extraction}

We designed data extraction forms to record authorship, year of publication, and details of study based on inclusion criteria. Two review authors extracted data independently. The following details were recorded when available.

- Trial methods: method of randomization, allocation, sample size, blinding methods, and losses at follow-up.

- Participants: country of origin, year of study, setting, sample size, inclusion, and exclusion criteria.

- Intervention: dosage of folic acid supplemented and duration of supplementation. 


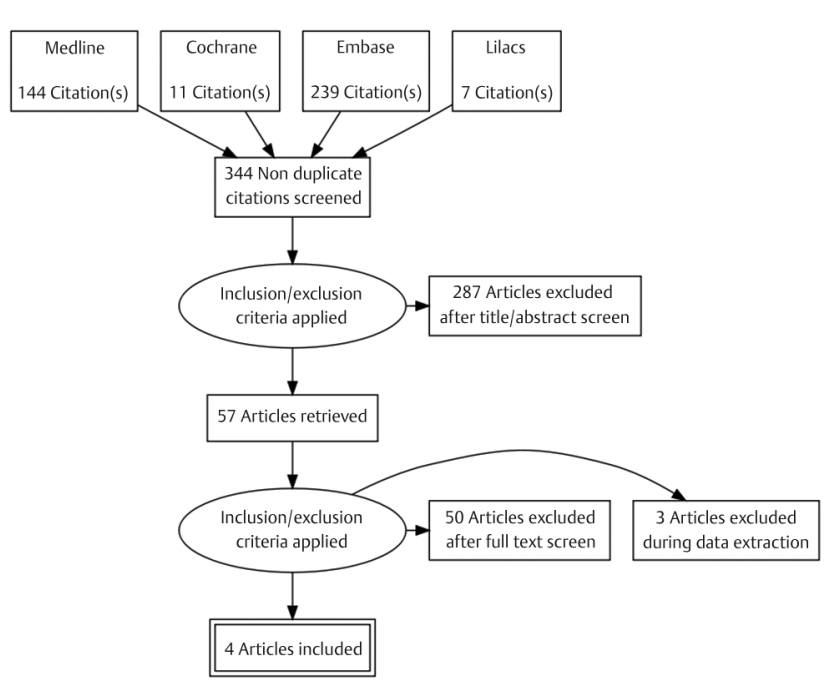

Fig. 1 Study selection PRISMA-P flow diagram.

- Control: no supplementation or low-dose folic acid supplementation.

- Outcomes: Occurrence or recurrence of $\mathrm{CL} \pm \mathrm{CP}$ or isolated CP.

In instances where there is more than one study from the same population by the same team of researchers, the more recent and relevant study has been included.

\section{Dealing with Missing Data}

In trials with missing data, we contacted the principal investigator by electronic mail.

\section{Data Synthesis}

\section{Assessment of Risk of Bias}

The assessment of the risks of bias was done using Cochrane's tool for assessing risk of bias as described in section 8.5 of the Cochrane Handbook for Systematic Reviews of Interventions. Two reviewers independently performed the assessment and any disagreements were resolved through discussion with the third reviewer.

Assessment of risk of bias performed for the RCT is as follows.

\section{Sequence Generation}

Generation of the randomization sequence was done using permuted blocks of random size-low risk of bias.

\section{Allocation}

Allocation concealment present-low risk of bias.

\section{Blinding}

Double blinding done-subjects, investigators, and researchers were blinded to randomization assignment-low risk of bias.

\section{Incomplete Outcomes Data}

Attrition and exclusions and the reasons for these have been reported. The changes in the recruitment such as reducing the length of participation and including isolated cleft palate early in the study and not later have all been mentioned in the publication-low risk of bias.

\section{Selective Outcome Reporting}

A study protocol has been published. The inclusion criteria in the protocol mentioned all cases of nonsyndromic cleft lip with or without cleft palate, both unilateral and bilateral, excluding cases with recognized syndromes and cleft palate only. In the overall analysis of outcome results these are included. But results after exclusion are also provided-low risk of bias.

\section{Other Bias}

As a clear study protocol has been published and all variations from the protocol and study period are stated in the article no other bias was detected.

\section{Results}

The study selection PRISMA-P flow diagram is given in -Fig. 1. The search yielded 401 articles, out of which four studies were selected based on the inclusion criteria-a single $\mathrm{RCT},{ }^{17}$ two prospective case-control trials, ${ }^{18,19}$ and a single case-control surveillance-Hungarian Case-Control Surveillance of Congenital Abnormalities ${ }^{15,20}$ on effect of periconceptional high-dose folic acid on prevention of isolated nonsyndromic clefts. The three case-control studies were on the prevention of recurrence of clefts, while the HCCSCA was on congenital abnormalities in general, and with clefts, was regarding occurrence rather than recurrence of clefts.

$\mathrm{CL}$ with or without $\mathrm{CP}$ was used as an inclusion criterion for two of the studies, but in effect only one study (Tolarova and Harris) has reported only on $\mathrm{CL} \pm \mathrm{CP}$. All others have included isolated $\mathrm{CP}$ also in the analysis. - Table 1 shows analysis of the results of the three case-control studies.

Czeizel et al had conducted two interventional studies earlier and the low dose of folic acid in the multivitamin supplemented was reported to be ineffective in preventing clefts. The HCCSCA ( - Fig. 2) like the other two studies was on several congenital anomalies of which cleft was one. Use of highdose folic acid is reported to bring about some reduction in both $\mathrm{CL} \pm \mathrm{CP}$ and $\mathrm{CP}$.

We came across a study protocol of a community based randomized clinical trial on effect of high-dose folic acid on prevention of congenital malformations in Italy and Netherlands. ${ }^{21}$ Contacting the principal investigator by electronic mail revealed that the analysis of the trial is still ongoing.

\section{Discussion}

The double blinded randomized control trial (RCT) by Wehby et $\mathrm{al}^{17}$ on the effect of periconceptional folic acid on prevention of recurrence of isolated cleft was conducted during the period 2004 to 2009. This involved 2,508 females and the dose of folic acid given to the study population was $4 \mathrm{mg}$ while the controls received the usual dose present in a multivitamin which is $0.4 \mathrm{mg}$. The outcome was based on 234 live births. The recurrence rates for oral clefts were 
Table 1 Study characteristics of case-control trials

\begin{tabular}{|c|c|c|c|}
\hline Studies & Wehby (2013) & Tolarova and Harris (1995) & $\begin{array}{l}\text { Briggs (1976; continuation of } \\
\text { peer study) }\end{array}$ \\
\hline Type of study & $\begin{array}{l}\text { Randomized double blind } \\
\text { control trial }\end{array}$ & $\begin{array}{l}\text { Nonrandomized prospective } \\
\text { case-control }\end{array}$ & Prospective case-control study \\
\hline Year & $2004-2009$ & 1976-1992 & 1958-1976 \\
\hline Study location & $\begin{array}{l}\text { Six craniofacial clinics in } \\
\text { Brazil }\end{array}$ & $\begin{array}{l}\text { Department of Medical Ge- } \\
\text { netics of the Czechoslovak } \\
\text { Academy of Sciences, } \\
\text { Prague }\end{array}$ & $\begin{array}{l}\text { Saint Barnabas Medical Center, } \\
\text { Livingston, New Jersey }\end{array}$ \\
\hline Type of cleft & $\begin{array}{l}\text { Isolated oral cleft recur- } \\
\text { rence }(C L \pm C P \text { and } C P)\end{array}$ & $\begin{array}{l}\text { Recurrence of oral cleft } \\
(C L \pm C P)\end{array}$ & $\begin{array}{l}\text { Recurrence of oral cleft } \\
(\mathrm{CL} \pm \mathrm{CP} \text { and } \mathrm{CP})\end{array}$ \\
\hline $\begin{array}{l}\text { Number of patients in study } \\
\text { population }\end{array}$ & 1,257 & $\begin{array}{l}221 \text { pregnancies at risk of } \\
\text { child with cleft }\end{array}$ & $\begin{array}{l}228 \text { pregnant mother at risk of } \\
\text { child with cleft }\end{array}$ \\
\hline $\begin{array}{l}\text { Dose of folic acid in study } \\
\text { population }\end{array}$ & $4 \mathrm{mg}$ & $10 \mathrm{mg}$ & $5 \mathrm{mg}$ \\
\hline Number of controls & 1,251 & $\begin{array}{l}1,901 \text { pregnant women at } \\
\text { risk of child with cleft }\end{array}$ & $\begin{array}{l}417 \text { pregnant mother at risk of } \\
\text { child with cleft }\end{array}$ \\
\hline Dose of folic acid in controls & $0.4 \mathrm{mg}$ & Nil & Nil \\
\hline Time of administration & $\begin{array}{l}\text { Before planned conception } \\
\text { and continued up to first } \\
\text { trimester }\end{array}$ & $\begin{array}{l}2 \text { months before planned } \\
\text { conception and continued } \\
\text { up to } 3 \text { months }\end{array}$ & $\begin{array}{l}\text { Before planned conception and } \\
\text { continued up to 5th month of } \\
\text { pregnancy }\end{array}$ \\
\hline $\begin{array}{l}\text { Cleft cases in study } \\
\text { population }\end{array}$ & $\begin{array}{l}3 \text { cases } \\
C L=1 \\
C P=1 \\
C L+C P=1\end{array}$ & $\begin{array}{l}3 \text { out of } 214 \text { informative } \\
\text { pregnancies }\end{array}$ & $\begin{array}{l}7 \text { cases } \\
C L+C P=3 \\
C P=3\end{array}$ \\
\hline Cleft cases in controls & 3 cases of $C L+C P$ & $\begin{array}{l}77 \text { out of } 1,901 \text { Informative } \\
\text { pregnancies }\end{array}$ & $\begin{array}{l}20 \text { cases } \\
C L+C P=15 \\
C P=5\end{array}$ \\
\hline $\begin{array}{l}\text { Method of statistical analy- } \\
\text { sis used }\end{array}$ & $\begin{array}{l}\text { Fischer's exact test and } \\
\text { Student } t \text {-test }\end{array}$ & $\begin{array}{l}\text { Chi-square and Fischer's } \\
\text { exact test }\end{array}$ & Not mentioned \\
\hline Recurrence risks & $\begin{array}{l}\text { Oral cleft recurrence was } \\
2.9 \% \text { in } 0.4 \mathrm{mg} \text { group } \\
\text { and } 0.8 \% \text { in } 4 \mathrm{mg} \text { group } \\
\text { (CP excluded) }\end{array}$ & $\begin{array}{l}65 \% \text { decrease in cleft recur- } \\
\text { rence found in supplemental } \\
\text { group }\end{array}$ & $\begin{array}{l}\text { Incidence rate in study group } \\
\text { for both } C L \pm C P \text { and } C P \text { was } \\
\text { lower than the control group } \\
(3.1 \% \text { vs. } 4.8 \%)\end{array}$ \\
\hline Adverse effects & Nil & Nil & Nil \\
\hline Additional comments & $\begin{array}{l}\text { Oral cleft recurrence was } \\
2.9 \% \text { in } 0.4 \mathrm{mg} \text { group } \\
\text { and } 1.6 \% \text { in } 4 \mathrm{mg} \text { group } \\
\text { when both } \mathrm{CL} \pm \mathrm{CP} \text { and } \\
\mathrm{CP} \text { included. } \\
\text { Recurrence rate was similar } \\
\text { between the two groups }\end{array}$ & $\begin{array}{l}\text { Best efficacy of supple- } \\
\text { mentation was found in the } \\
\text { subset with unilateral cleft } \\
\text { ( } 3.51 \% \text { vs. } 0.6 \% \text { ), a decrease } \\
\text { by } 82.6 \% \text {. } \\
\text { No difference in the sub- } \\
\text { group of female probands } \\
\text { with bilateral cleft }\end{array}$ & $\begin{array}{l}\text { Incidence of } 1.9 \% \text { in the treat- } \\
\text { ed group for } C L+C P(1.9 \% \text { vs. } \\
5.5 \%) \text {. } \\
\text { Incidence of } 6 \% \text { in the treated } \\
\text { group for } C P(6 \% \text { vs. } 3.5 \%)\end{array}$ \\
\hline
\end{tabular}

Abbreviations: $\mathrm{CL}$, cleft palate; $\mathrm{CP}$, cleft lip.

found to be similar between the two groups $(2.9 \%$ in the $0.4 \mathrm{mg}$ and $2.5 \%$ in the $4 \mathrm{mg}$ group) when cases of cleft lip with or without cleft palate as well as isolated cleft palate in the study groups were included. This shows a wide difference from the historic recurrence rate postfolic acid fortification (6.3\%; $p=0.0009$ when both folic acid groups are combined). But isolated cleft palate was not in the inclusion criteria of the study and excluding this, the recurrence rate is $1.6 \%$. Apart from this, one of the cases was diagnosed as Vander-Woude's syndrome (VWS), and hence excluded, as this is the most common syndromic form of oral cleft with a $50 \%$ recurrence risk. The recurrence rate was significantly low in
$4 \mathrm{mg}$ group when cleft lip with palate alone was considered $(0.8 \%)$, while this was $2.9 \%$ in the $0.4 \mathrm{mg}$ group.

The researchers have concluded that the small sample limits their ability to arrive at a formal statistical inference to compare the effect of high- and low-dose folic acid on cleft recurrence.

No compromise in fetal growth was observed in any of the groups.

The Hungarian Case-Control Surveillance of Congenital Abnormalities from 1980 to 1996 regarding high-dose folic acid in the periconceptional period was a study on various congenital anomalies. Clefts was not the outcome 


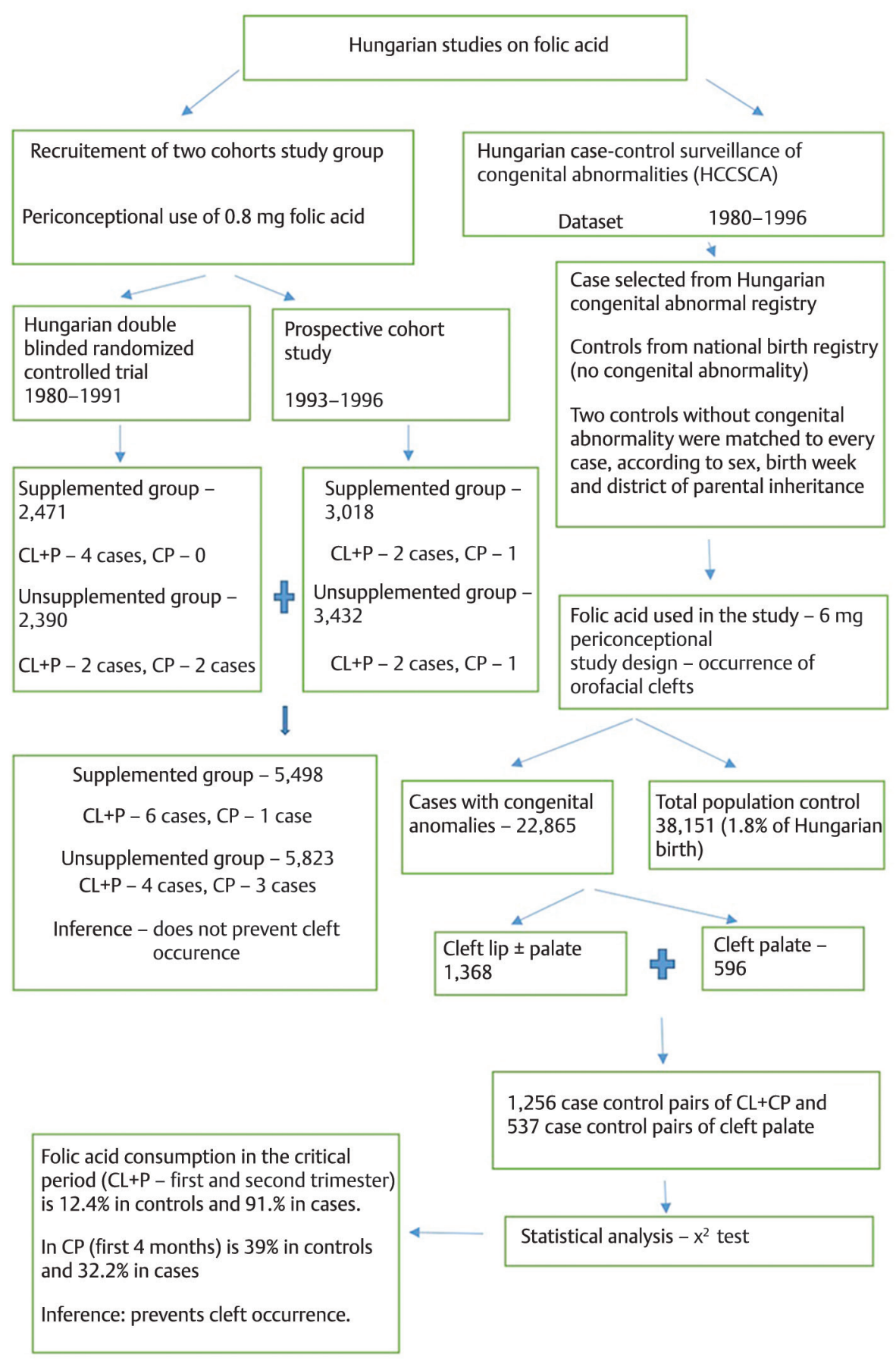

Fig. 2 Hungarian Study flow chart.

of primary interest, it was only one of the outcomes being evaluated and included isolated cleft lip with or without cleft palate.

The cases were obtained from the Hungarian Congenital Abnormality Registry (HCAR) and consisted of 22,843 malformed offspring and control group from the National Birth Registry consisting of 38,151 cases.

The dose of folic acid was not recorded in $50 \%$ of the pregnant women. But in the validation study based on 600 pregnant women, the dose of folic acid used was found to be $3 \mathrm{mg}$ in $22.5 \%, 6 \mathrm{mg}$ in $68.6 \%$, and $9 \mathrm{mg}$ in $8.9 \%$. There were 1,374 cases of $\mathrm{CL} \pm \mathrm{CP}$ and 601 cases of $\mathrm{CP}$.
Though the multivitamin with low dose $(0.8 \mathrm{mg})$ of folic acid in the intervention trials ${ }^{14}$ by Czeizel et al did not show reduction in orofacial clefts, the high dose in the HCCSCA demonstrated some preventive effect on clefts especially cleft palate.

The nonrandomized case-control study by Tolarova and Harris was specifically on recurrence of nonsyndromic isolated $\mathrm{CL} \pm \mathrm{CP}$. 221 pregnancies in females at risk of $\mathrm{CL} \pm \mathrm{CP}$ were the study population. They were given multivitamin with $10 \mathrm{mg}$ folic acid from at least 2 months before conception to 3 months after. The control group consisted of 1,901 females at risk of $\mathrm{CL} \pm \mathrm{CP}$ with no supplementation. The incidence 
was 1.4 and $4.05 \%$ in the supplemented and control groups respectively, indicating a risk reduction of $65.4 \%$. Best results were found with unilateral cleft ( 3.5 vs. $0.61 \%$ ), a decrease by $82.6 \%$.

No difference was found in female probands with bilateral cleft.

Publication by Briggs ${ }^{19}$ is a continuation of the Peer et al ${ }^{22}$ study, as a prospective case-control study on effect of $5 \mathrm{mg}$ of folic acid during the periconceptional period on recurrence of oral clefts.

The incidence in the pregnancy after having had a child with isolated cleft and subsequent pregnancies are available separately. The study group consisted of 228 women with previous cleft children who were supplemented with vitamins and the control group 417 women with previous clefts who were not supplemented. Of the 228,161 had children with CL $\pm \mathrm{CP}$ and the recurrence was $3(1.9 \%)$. There were 67 with cleft palate alone and the recurrence was 4 (6\%), a total recurrence rate of $3.1 \%$. The incidence in the control group was $5.5 \%, 3.5 \%$, and $4.8 \%$ for $\mathrm{CL} \pm \mathrm{CP}, \mathrm{CP}$ alone, and total respectively.

The figures show an impressive effect when the deformities are taken separately in that there is a significant reduction in $\mathrm{CL} \pm \mathrm{CP}$ in the supplemented group. The recurrence rate for $\mathrm{CP}$ alone is considerably high. There is an overall reduction in recurrence of $1.7 \%$ when compared with the unsupplemented group.

The dose of folic acid in the high dose studies varied widely. The inclusion criteria, study target as in $\mathrm{CL} \pm \mathrm{CP}$ and isolated $\mathrm{CP}$, method of supplementing folic acid-alone or in combination with other vitamins, and variations in control group management as in no folic acid or low-dose folic acid are some of the heterogeneities when comparing the four studies. Due to the various heterogeneities in the studies a meta-analysis is not justifiable.

Of the four studies available to date, the most recent one itself is almost 10 years and the other three more than 25 years, demonstrating the paucity of such studies in current times.

The studies were conducted in Europe, United States, and South America. There are none from Asian or African countries. Since the incidence of cleft is maximum in Asian countries, absence of studies from this continent is a significant drawback.

\section{Conclusions}

There are several gaps in the evidence regarding the efficacy of high-dose folic acid in prevention of oral clefts. From the data obtained from the available studies (Level 1b evidence for the RCT and Level 3b evidence for the case-control studies based on Oxford Centre for Evidence-based Medicine Levels of Evidence), there does seem to be a strong association between high-dose folic acid administration and prevention of isolated $\mathrm{CL} \pm \mathrm{CP}$. With regard to isolated $\mathrm{CP}$, the link appears to be very weak. The fact that these two entities are etiologically different could be the reason for the difference in behavior.
None of the studies have reported any adverse side effects from supplementation of high-dose folic acid during the periconceptional period.

Considering the high-cost related to management of cleft cases and psychological and social burden associated, it might be justifiable to supplement high-dose folic acid during periconceptional period to high risk females to prevent recurrence of clefts.

Multicenter randomized controlled trials in different continents with large number of cases and controls assessing the efficacy of specifically high-dose folic acid rather than multivitamins containing folic acid in prevention of occurrence and recurrence of orofacial clefts are required. The dose of folic acid for the recurrence prevention studies need to be standardized to $5 \mathrm{mg}$ as done for neural tube defects. It might be prudent to conduct numerous trials in Asian countries like India as numbers are easily achievable due to the very high incidence rates of cleft in this continent. The studies should be done separately on $\mathrm{CL} \pm \mathrm{CP}$ and isolated $\mathrm{CP}$ as there is a significant difference in behavior in response to folic acid supplementation from studies so far.

\section{Protocol Registered with PROSPERO}

(International prospective register of systematic reviews). Registration number: CRD42018090927.

\section{Conflict of Interest}

None.

\section{Acknowledgment}

The review team would like to thank Pip Divall, Clinical Librarian Service Manager, Louise Hull, Clinical Librarian, and the Education Library Team, University Hospitals of Leicester for their support with the search and material for this review.

\section{References}

1 Wehby GL, Ohsfeldt RL, Murray JC. Health professionals' assessment of health-related quality of life values for oral clefting by age using a visual analogue scale method. Cleft Palate Craniofac J 2006;43(4):383-391

2 Wehby GL, Cassell CH. The impact of orofacial clefts on quality of life and healthcare use and costs. Oral Dis 2010;16(1):3-10

3 Stuppia L, Capogreco M, Marzo G, et al.Genetics of syndromic and nonsyndromic cleft lip and palate. J Craniofac Surg 2011;22(5):1722-1726

4 Little J, Gilmour M, Mossey PA, et al. ITS MAGIC Collaboration. Folate and clefts of the lip and palate-a U.K.-based case-control study: Part II: Biochemical and genetic analysis. Cleft Palate Craniofac J 2008;45(4):428-438

5 Shaw GM, Todoroff K, Finnell RH, Rozen R, Lammer EJ. Maternal vitamin use, infant C677T mutation in MTHFR, and isolated cleft palate risk. Am J Med Genet 1999;85(1):84-85

6 Jugessur A, Wilcox AJ, Lie RT, et al.Exploring the effects of methylenetetrahydrofolate reductase gene variants C677T and A1298C on the risk of orofacial clefts in 261 Norwegian case-parent triads. Am J Epidemiol 2003;157(12):1083-1091

7 Chevrier C, Perret C, Bahuau M, et al.Fetal and maternal MTHFR C677T genotype, maternal folate intake and 
the risk of nonsyndromic oral clefts. Am J Med Genet A 2007; $143 \mathrm{~A}(3): 248-257$

8 MRC Vitamin Study Research Group. Prevention of neural tube defects: results of the Medical Research Council Vitamin Study. Lancet 1991;338(8760):131-137

9 Wilcox AJ, Lie RT, Solvoll K, et al.Folic acid supplements and risk of facial clefts: national population based case-control study. BMJ 2007;334(7591):464

10 Little J, Gilmour M, Mossey PA, et al.ITS MAGIC collaboration. Folate and clefts of the lip and palate-a U.K.-based case-control study: Part I: Dietary and supplemental folate. Cleft Palate Craniofac J 2008;45(4):420-427

11 van Rooij IALM, Ocké MC, Straatman H, Zielhuis GA, Merkus HM, Steegers-Theunissen RP. Periconceptional folate intake by supplement and food reduces the risk of nonsyndromic cleft lip with or without cleft palate. Prev Med 2004;39(4):689-694

12 De-Regil LM, Peña-Rosas JP, Fernández-Gaxiola AC, Rayco-Solon P. Effects and safety of periconceptional oral folate supplementation for preventing birth defects. Cochrane Database Syst Rev 2015;2015(12):CD007950

13 Jahanbin A, Shadkam E, Miri HH, Shirazi AS, Abtahi M. Maternal folic acid supplementation and the risk of oral clefts in offspring. J Craniofac Surg 2018;29(6):e534-e541

14 Czeizel AE, Dobó M, Vargha P. Hungarian cohort-controlled trial of periconceptional multivitamin supplementation shows a reduction in certain congenital abnormalities. Birth Defects Res A Clin Mol Teratol 2004;70(11):853-861
15 Czeizel AE. The primary prevention of birth defects: Multivitamins or folic acid? Int J Med Sci 2004;1(1):50-61

16 Johnson CY, Little J. Folate intake, markers of folate status and oral clefts: is the evidence converging? Int J Epidemiol 2008;37(5):1041-1058

17 Wehby GL, Félix TM, Goco N, et al.High dosage folic acid supplementation, oral cleft recurrence and fetal growth. Int J Environ Res Public Health 2013;10(2):590-605

18 Tolarova M, Harris J. Reduced recurrence of orofacial clefts after periconceptional supplementation with high-dose folic acid and multivitamins. Teratology 1995;51(2):71-78

19 Briggs RM. Vitamin supplementation as a possible factor in the incidence of cleft lip/palate deformities in humans. Clin Plast Surg 1976;3(4):647-652

20 Czeizel AE, Tímár L, Sárközi A. Dose-dependent effect of folic acid on the prevention of orofacial clefts. Pediatrics 1999;104(6):e66

21 Bortolus R, Blom F, Filippini F, et al. Italian and Dutch folic acid trial study groups. Prevention of congenital malformations and other adverse pregnancy outcomes with $4.0 \mathrm{mg}$ of folic acid: community-based randomized clinical trial in Italy and the Netherlands. BMC Pregnancy Childbirth 2014;14(1):166

22 Peer LA, Gordon HW, Bernhard WG. Effects of vitamins on human teratology. Plast Reconstr Surg 1964;34:358-362 